\title{
Natural Convection Heat Transfer from Discretely Heated Vertical Channel: Effect of the Surface Radiation
}

\author{
Bugra Sarper $^{1}$, Mehmet Saglam², Orhan Aydin', Mete Avci \\ ${ }^{1}$ Gumushane University \\ Department of Mechanical Engineering \\ 29100 Gumushane, Turkey \\ ${ }^{2}$ Karadeniz Technical University \\ Department of Mechanical Engineering \\ 61080 Trabzon, Turkey \\ bugrasarper@gumushane.edu.tr; mehmetsaglam@ktu.edu.tr; oaydin@ktu.edu.tr; mavci@ktu.edu.tr
}

\begin{abstract}
In this study, three dimensional natural convection with or without radiation in a discretely heated vertical channel is studied experimentally and numerically. One of the channel walls is discretely heated by four flush-mounted heaters and the others are insulated. The study is focused on the effects of surface radiation on reverse flow at the outlet and convection heat transfer from the heater surfaces. The range of the modified Grashof number covers the values between $3.82 \times 10^{6}$ and $1.53 \times 10^{7}$. Surface to surface radiation heat transfer is considered while the medium is considered as non-participating. Emissivity of the heater surfaces and other surfaces are 0.05 and 0.9 , respectively. Temperature measurements are performed in the experimental study. ANSYS Fluent software is used in the computational analysis. The Nusselt number as well as the velocity and temperature profiles are obtained for various values of the modified Grashof number.
\end{abstract}

Keywords: Natural convection, radiation, discrete heating, electronics cooling

\section{Introduction}

As the processing capacity of electronic devices increase day by day, their size gets smaller. Depending on the processing capacity and the compact design of the device, heat generation by a circuit component also increases, which causes an excessive temperature rise. This temperature rise may result in malfunctions based on thermal stresses in the circuit components. For this reason, thermal management of electronic devices has become important. In order to ensure safe and continuous operation, component temperatures must be kept below the safety limit specified by manufacturer. Convection heat transfer is an option for cooling. Different modes of convection can be used for cooling of electronic equipments. Natural, mixed and forced convection regimes are widely used. Natural convection is effective for cooling of low power electronic devices such as consumer electronics. Also, it is preferred because of its easy application and safety. In addition, conduction and radiation heat transfer is effective and should be taken into account.

There are numerous studies related to convection heat transfer in vertical or inclined channels in the existing literature. Many of these works have investigated different convection regimes. However, studies examining the effects of radiation on flow and heat transfer are limited. Numerical and experimental studies on natural convection heat transfer were performed for different working parameters and channel configurations [1-9]. Mixed convection heat transfer was studied for different heater configurations, various inclination angles of the channel and different flow conditions [10-14]. Xu et al. [15] numerically investigated turbulent forced convection between two parallel plates with discrete flush-mounted heaters. Conjugate-mixed convection with radiation in a vertical channel was examined in Refs. [16-19]. Premachandran and Balaji [20] analyzed the effects of material and surface properties of channel walls and heaters, the Grashof number and the Reynolds number on conjugate mixed convection with radiation in a discretely heated vertical channel. They pointed out that for an accurate prediction of heat transfer and temperature distribution, radiation heat transfer should not be ignored. Londhe and Rao [21] numerically studied mixed convection-radiation heat transfer in a discretely heated vertical channel. 
They stated that heater temperature is less when the heater is positioned near the entrance of the channel and radiation heat transfer must be considered especially for the natural convection regime.

The aim of the study is to investigate the buoyancy-induced flow and heat transfer in a vertical channel with discrete heaters placed on its one wall. Two cases will be examined in this study. In the first case, radiative heat transfer occurs between the heaters and remaining surfaces. In the second case, radiative heat transfer between surfaces is neglected. Special focus will be given on the effects of surface radiation on reverse flow condition at the channel exit and convection heat transfer from the heater surfaces.

\section{Experimental Apparatus and Procedure}

The schematic of the test section and photograph of the experimental set-up are shown in Fig 1. The experimental setup consists of a computer, a data acquisition system, a DC power supply, an uninterruptable power supply and the test section. Experiments are carried out in a vertical channel with four identical flush-mounted discrete heat sources on its one wall. The remaining surfaces are thermally insulated. The channel walls are made of $10 \mathrm{~mm}$ thick $\left(\mathrm{t}_{\mathrm{p}}\right)$ polycarbonate plate $\left(\mathrm{k}_{\mathrm{p}}=0.2167 \mathrm{~W} / \mathrm{mK}\right)$. Heater surfaces are made of copper $\left(\mathrm{k}_{\mathrm{cu}}=387.6 \mathrm{~W} / \mathrm{mK}\right)$ with $1.5 \mathrm{~mm}$ thickness $\left(\mathrm{t}_{\mathrm{cu}}\right), 25.4 \mathrm{~mm}$ length $\left(\mathrm{L}_{\mathrm{h}}\right)$ and $152.4 \mathrm{~mm}$ depth (D). The copper surfaces are heated with flexible heaters from the back of its surfaces. The thickness of the heaters $\left(\mathrm{t}_{\mathrm{h}}\right)$ are $0.35 \mathrm{~mm}$. Thermal insulation is provided with XPS foamboard $\left(\mathrm{k}_{\text {ins }}=0.035 \mathrm{~W} / \mathrm{mK}\right)$ having a thickness of $30 \mathrm{~mm}$ and it is mounted on the back of flexible heaters and polycarbonate plate. Total length of the channel $\left(\mathrm{L}_{\text {tot }}\right)$ is $314.33 \mathrm{~mm}$, unheated inlet length $\left(\mathrm{L}_{\mathrm{in}}\right)$ is $25.4 \mathrm{~mm}$, unheated outlet length $\left(\mathrm{L}_{\text {out }}\right)$ is $130.18 \mathrm{~mm}$ and spacing between each of the heaters (s) are $19.05 \mathrm{~mm}$. Also, channel width (W) is $25.4 \mathrm{~mm}$ and channel depth (D) is $152.4 \mathrm{~mm}$. For the dimensions considered, hydraulic diameter of the channel $\left(D_{h}\right)$ is $43.54 \mathrm{~mm}$. Copper surfaces are polished $(\varepsilon=0.05)$ and polycarbonate surfaces are treated as black surfaces $(\varepsilon=0.9)$. Air is used as the working fluid and it enters the channel from the bottom.

Three $0.4 \mathrm{~mm}$-diameter copper-constantan thermocouples are placed $1 \mathrm{~mm}$ under each of the copper plates. Eighteen thermocouples are used along the centerline of the polycarbonate plates and two thermocouples are used at the inlet-outlet sections of the channel. Also, twelve thermocouples are located at the back of heaters and insulation material. Experiments are carried out in an air-conditioned room and test section is placed in a chamber in order to minimize environmental impacts. Before beginning of each experiment, temperature and relative humidity were kept at $24^{\circ} \mathrm{C}$ and $50 \%$ by an airconditioner. For each measurement, the flow is considered to have reached steady state when temperature measurements don't change with time any more.

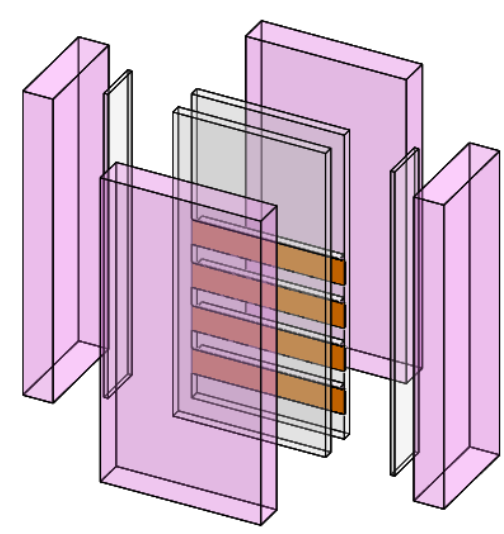

(a)

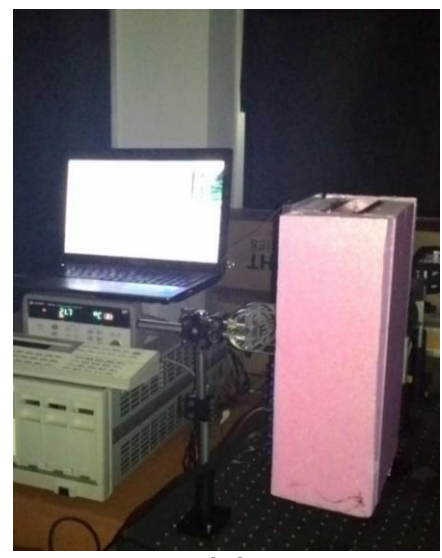

(b)

Fig. 1: (a) Schematic of the problem, (b) experimental set-up.

\section{Numerical Study}

In the numerical part of the study, ANSYS Fluent software is used to solve governing equations. The flow is assumed to be three dimensional, steady and laminar. Constant fluid properties are assumed except for the density change. Density change with temperature that induce buoyancy forces is modelled by adopting Boussinesq approximation. In addition, 
radiative heat transfer between surfaces and conductive heat transfer inside the walls are taken into account. The schematic of the problem is shown in Fig. 2.

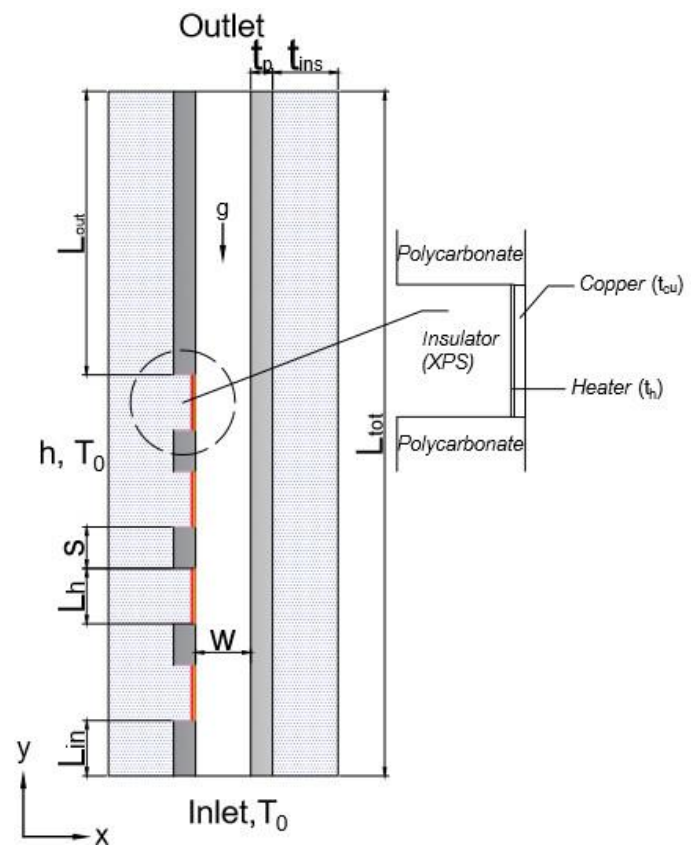

Fig. 2: Model geometry.

\subsection{Governing Equations}

The governing equations for a 3D, steady, incompressible, laminar flow are given as follows:

In the fluid region:

$$
\begin{gathered}
\frac{\partial u}{\partial x}+\frac{\partial v}{\partial y}+\frac{\partial w}{\partial z}=0 \\
u \frac{\partial u}{\partial x}+v \frac{\partial u}{\partial y}+w \frac{\partial u}{\partial z}=-\frac{1}{\rho} \frac{\partial p}{\partial x}+v\left(\frac{\partial^{2} u}{\partial x^{2}}+\frac{\partial^{2} u}{\partial y^{2}}+\frac{\partial^{2} u}{\partial z^{2}}\right) \\
u \frac{\partial v}{\partial x}+v \frac{\partial v}{\partial y}+w \frac{\partial v}{\partial z}=-\frac{1}{\rho} \frac{\partial p}{\partial y}+v\left(\frac{\partial^{2} v}{\partial x^{2}}+\frac{\partial^{2} v}{\partial y^{2}}+\frac{\partial^{2} v}{\partial z^{2}}\right)+\beta g\left(T-T_{o}\right) \\
u \frac{\partial w}{\partial x}+v \frac{\partial w}{\partial y}+w \frac{\partial w}{\partial z}=-\frac{1}{\rho} \frac{\partial p}{\partial z}+v\left(\frac{\partial^{2} w}{\partial x^{2}}+\frac{\partial^{2} w}{\partial y^{2}}+\frac{\partial^{2} w}{\partial z^{2}}\right) \\
u \frac{\partial T}{\partial x}+v \frac{\partial T}{\partial y}+w \frac{\partial T}{\partial z}=\alpha\left(\frac{\partial^{2} T}{\partial x^{2}}+\frac{\partial^{2} T}{\partial y^{2}}+\frac{\partial^{2} T}{\partial z^{2}}\right)
\end{gathered}
$$

where $u, v$ and $w$ are the velocity components in the $x, y$ and $z$ directions. $\rho$ is the density and $v$ is the kinematic viscosity of the fluid. $T_{0}$ is the reference ambient temperature. $\alpha$ and $\beta$ is the thermal diffusivity and thermal expansion coefficient of the fluid, respectively.

In the solid region: 


$$
\frac{\partial^{2} T}{\partial x^{2}}+\frac{\partial^{2} T}{\partial y^{2}}+\frac{\partial^{2} T}{\partial z^{2}}+\frac{\dot{q}}{k}=0
$$

The modified Grashof number is defined as a function of volumetric heat generation $(\dot{q})$ inside the heaters and hydraulic diameter of the channel.

$$
G r_{D h}^{*}=\frac{g \beta \dot{q} D_{h}^{4} t_{h}}{k v^{2}}
$$

where $k$ is the thermal conductivity of the material.

The hydraulic diameter is defined as:

$$
D_{h}=\frac{4 W D}{2(W+D)}
$$

The heat transfer coefficient is:

$$
q_{\text {conv }}=h\left(T_{s}-T_{0}\right)
$$

where $q_{\text {conv }}$ and $T_{s}$ denote the convection heat flux from and surface temperature, respectively. The local and average Nusselt numbers are calculated by the following equations, respectively:

$$
N u=\frac{h D_{h}}{k_{f}}, \quad N u_{a v e}=\frac{\bar{h} D_{h}}{k_{f}}
$$

\subsection{Boundary Conditions}

Pressure inlet and pressure outlet boundary conditions are applied at the channel inlet and channel exit, respectively. The working fluid, air, is assumed to be nonparticipating medium and its temperature is $24^{\circ} \mathrm{C}$ at the inlet. For radiation calculation, radiation boundary condition is also specified. External black body temperature is $24^{\circ} \mathrm{C}$ at the inlet-outlet boundaries and internal emissivity value of these boundaries is 1 . Emissivity value of the black channel surface and the polished copper surfaces are 0.9 and 0.05 , respectively. Coupled boundary condition is used at wall-to-wall and wall-tofluid boundaries. In addition, convection boundary condition with the convection heat transfer coefficient, $\mathrm{h}=5 \mathrm{~W} / \mathrm{m}^{2} \mathrm{~K}$ is implemented at the outer surfaces of the insulation material.

\subsection{Numerical Method}

Numerical study is performed using ANSYS Fluent CFD software which is based on control volume method. Pressure based-segregated solver is used for incompressible flow. In this method, governing equations are solved sequentially. SIMPLE algorithm is used for pressure-velocity coupling. Momentum and energy equations are discretized by a second order upwind scheme and pressure interpolation is provided by PRESTO scheme which is recommended for natural convection flows. Radiation heat exchange between the surfaces is taken into account by surface to surface radiation method (S2S) which assumes the surfaces gray and diffuse [22]. Convergence criterion is chosen as $10^{-5}$ for continuity, momentum energy and radiation equations. 


\subsection{Mesh Structure}

In the numerical studies, a uniform mesh structure is applied in both coordinates. Smaller mesh size is used in the flow domain, interior of the heaters and channel walls where the heat transfer through the boundaries is important. In order to calculate the temperature gradients within the thermal boundary layer accurately, finer mesh is adopted in the $\mathrm{x}$ direction while coarse mesh covers the $\mathrm{y}$ and $\mathrm{z}$ directions. A mesh independence study has been performed using four different cell numbers $(1265616,1736856,2235024$ and 2706264 cells) and results are obtained for the average Nusselt number values on heater surfaces. The mesh independence study shows that significant changes have not been obtained between the 1736856 and 2235024 cells and solutions have been performed with 1736856 cells.

Mesh independent results were compared against our experimental measurements on heated and unheated walls at $\mathrm{Gr}^{*}{ }_{\mathrm{Dh}}=1.53 \times 10^{7}$. It is clearly seen from Fig. 3 that numerical results are agreed well with the experimental measurements. Maximum temperature difference between the experimental and numerical temperature values is $2.5^{\circ} \mathrm{C}$.

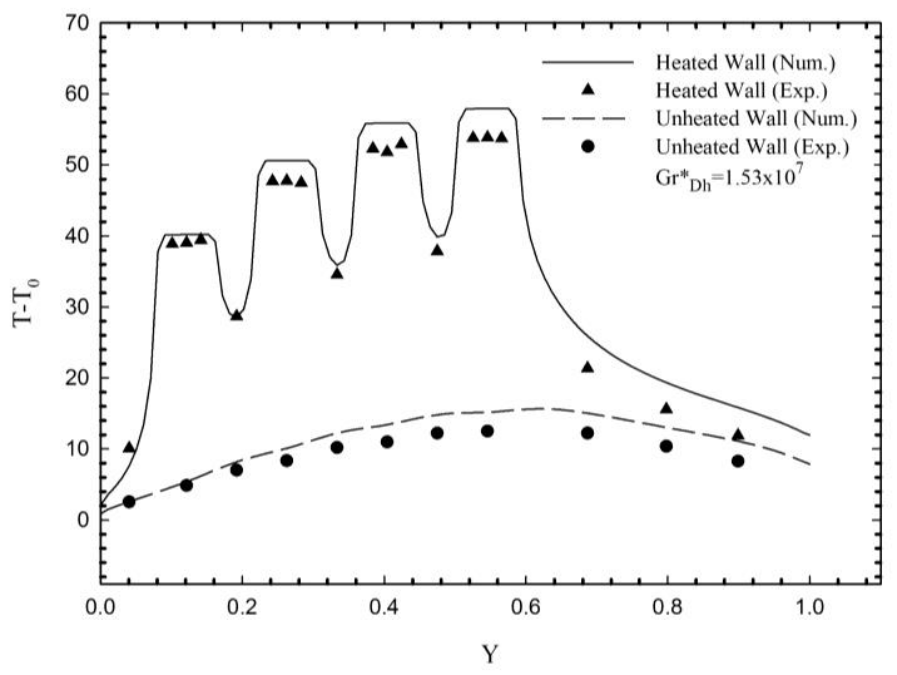

Fig. 3: Comparison of the numerical and experimental results.

\section{Results and Discussion}

Heated and unheated wall temperatures for different values of the modified Grashof number with or without radiation heat exchange between the surfaces are given in Fig. 4. In the numerical modeling, volumetric heat generation was imposed both of the heaters. The modified Grashof number defined in Eq. (7) is also a function of volumetric heat generation. Thus, surface temperatures of the heaters and channel walls increase with the modified Grashof number. It is clearly seen from the figure, surface temperature rises sharply from the entrance of the channel and heater temperature remains constant due to high conductivity of copper. On the heaters, surface temperatures are higher than unheated sections and surface temperatures decrease towards the channel exit. Air enters the channel at ambient temperature, $24^{\circ} \mathrm{C}$, heats by contacting the heaters and moves upward under the influence of buoyancy force. Heat transfer decreases due to the increase in air temperature when fluid moves upward, and, therefore, heater temperatures increase. The radiation heat exchange is very important, and it influences buoyancy induced flow depending on boundary layer formation at the unheated wall-to-fluid interface. From the entrance of the channel, surface temperatures at the unheated wall rise, then reach the highest value at the opposite section of the heater 4 and finally decrease towards the channel exit. When the radiation heat exchange is neglected, convection heat transfer decreases, therefore heater temperatures increase, and a remarkable change in surface temperatures at the unheated wall isn't seen (see Fig. 4b). 


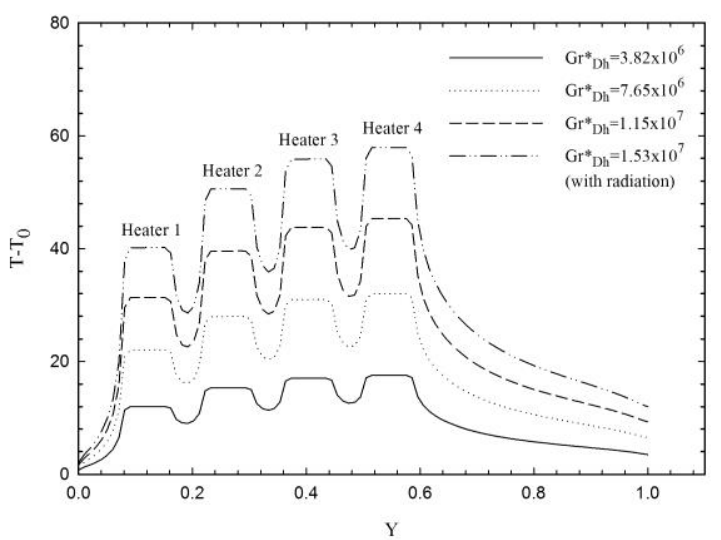

(a1)

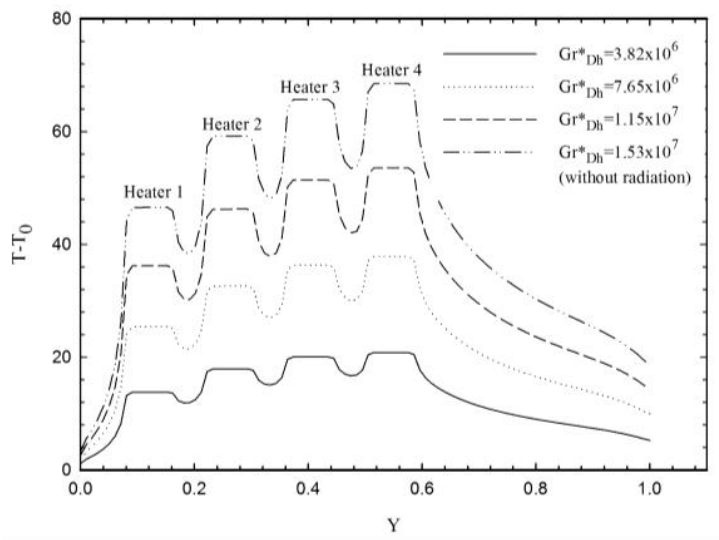

(b1)

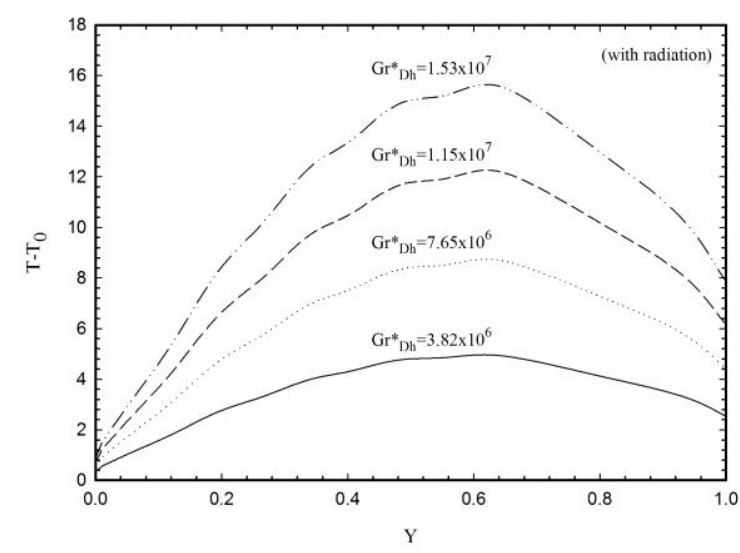

(a2)

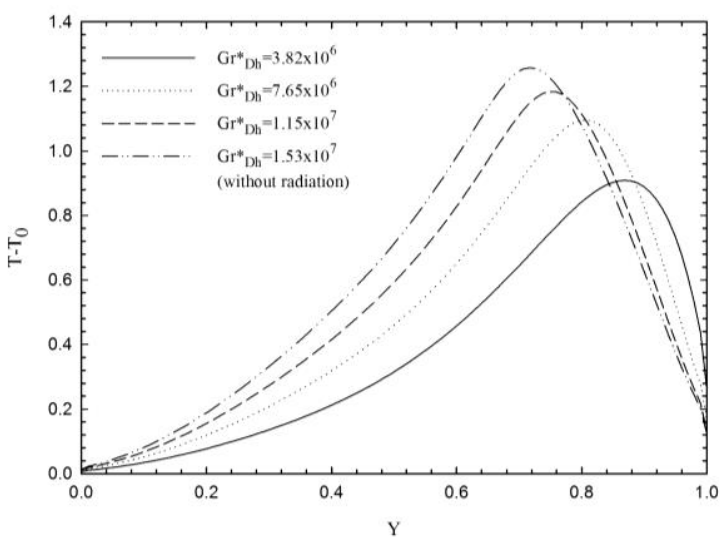

(b2)

Fig. 4: Surface temperatures with or without radiation heat transfer: (a) heated wall, (b) unheated wall.

Vertical velocity distribution at different coordinates in flow domain is shown in Fig. 5 at $\mathrm{Gr}^{*}{ }_{\mathrm{Dh}}=1.53 \times 10^{7}$. At $\mathrm{L}_{\text {tot }} / 4$, where the surface temperature at the heated wall is low, velocity distribution is almost symmetrical. As air ascends along the channel, buoyancy effects become significant due to the temperature rise of fluid and heated wall and, velocity values become higher near the heated wall. The surface temperature of the unheated wall increases when radiation heat exchange between surfaces is taken into account. When radiation heat exchange is not included in the analysis, a reverse flow near the unheated wall is observed. The reverse flow disappears when the radiation is included (see Fig. 5b).

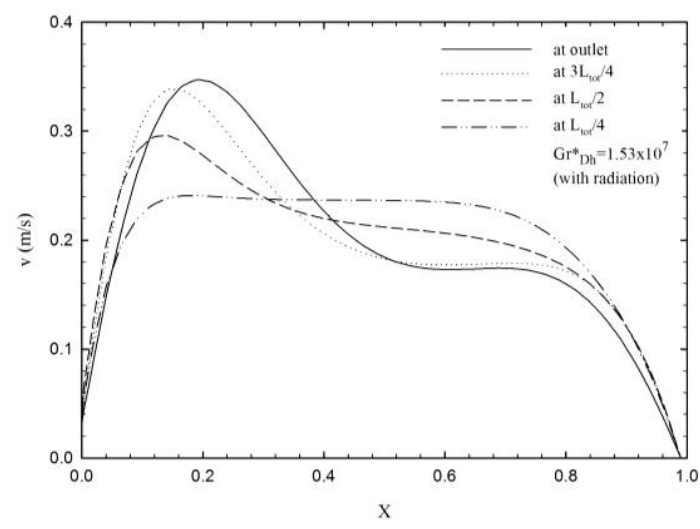

(a)

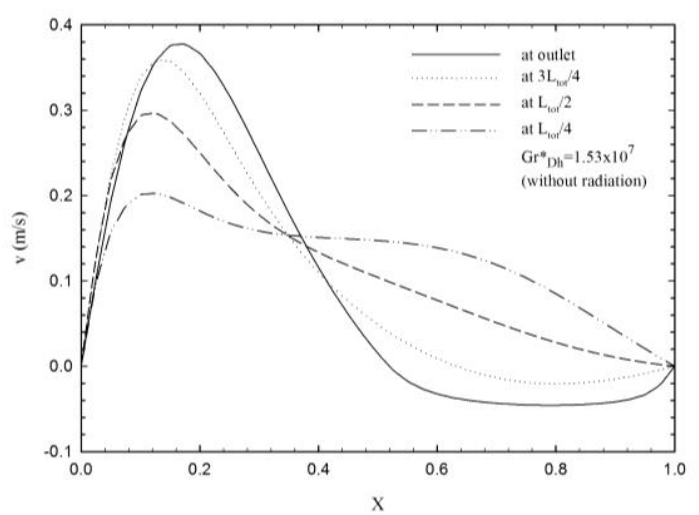

(b)

Fig. 5: Variation of the vertical velocity at different coordinates. 
The variation of the average Nusselt number with the modified Grashof number for the cases with or without radiation heat exchange is represented in Fig. 6. It is seen from the figure, the average Nusselt number reaches the highest value at the entrance and decreases due to the increase in air temperature through the channel in all the cases considered. An increase in $\mathrm{Gr}^{*}{ }_{\mathrm{Dh}}$ increases $\mathrm{Nu}$, as expected. Including the radiation heat exchange in the analysis increases heat transfer more.

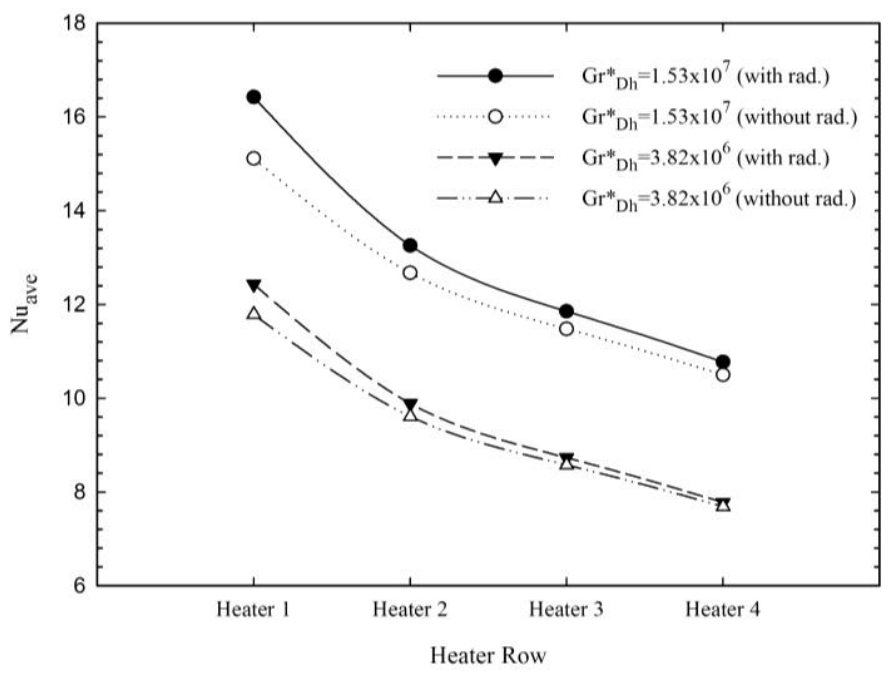

Fig 6: Average Nusselt number variation.

\section{Conclusion}

Three dimensional natural convection in a discretely heated vertical channel have been analyzed experimentally and numerically. The effects of the modified Grashof number and surface radiation on natural convection from the heaters and reverse flow have been investigated. Some of the important findings obtained in the study can be presented as follows:

- Surface temperatures of the heated wall increase from the entrance of the channel and decrease towards the channel exit in both cases.

- Surface temperatures of the unheated wall increase especially at the opposite section of the heaters due to the surface radiation.

- A significant change in surface temperatures of the unheated wall does not occur when surface radiation is not taken into account in the numerical computations.

- Surface radiation has significant effects on buoyancy-induced flow. The reverse flow observed for the case without surface radiation exchange is shown to disappear with surface radiation exchange.

- Convection heat transfer is more effective in the channel entrance where the fluid is colder, and it decreases gradually towards the channel.

- Surface radiation is effective on convection heat transfer depending on the direction of the buoyancy forces.

- Convection heat transfer increases with an increase in the modified Grashof number.

\section{Acknowledgements}

This study is supported by The Scientific and Technological Research Council of Turkey (TUBITAK) with project number of $114 \mathrm{M} 589$.

\section{References}

[1] W. Yan, T. Lin, "Natural convection heat transfer in vertical open channel flows with discrete heating," International Communications in Heat and Mass Transfer, vol. 14, no. 2, pp. 187-200, 1987.

[2] M. Chadwick, B. Webb, H. Heaton, "Natural convection from discrete heat sources in a vertically vented rectangular enclosure," Experimental Heat Transfer, vol. 4, no. 3, pp. 199-216, 1991. 
[3] D. Elpidorou, V. Prasad and V. Modi, "Convection in a vertical channel with a finite wall heat source," International Journal of Heat and Mass Transfer, vol. 34, no. 2, pp. 573-578, 1991.

[4] C. Choi and A. Ortega, "Mixed convection in an inclined channel with a discrete heat source," International Journal of Heat and Mass Transfer, vol. 36, no. 12, pp. 3119-3134, 1993.

[5] M. Fujii, S. Gima, T. Tomimura, X. Zhang, "Natural convection to air from an array of vertical parallel plates with discrete and protruding heat sources," International Journal of Heat and Fluid Flow, vol. 17, no. 5, pp. 483-490, 1996.

[6] R. Bessaih, M. Kadja, "Turbulent natural convection cooling of electronic components mounted on a vertical channel," Applied Thermal Engineering, vol. 20, no. 2, pp. 141-154, 2000.

[7] O. Manca, S. Nardini, V. Naso, "Effect on Natural Convection of the Distance Between an Inclined Discretely Heated Plate and a Parallel Shroud Below," Journal of Heat Transfer, vol. 124, no. 3, pp. 441, 2002.

[8] G. Desrayaud, A. Fichera and G. Lauriat, "Natural convection air-cooling of a substrate-mounted protruding heat source in a stack of parallel boards," International Journal of Heat and Fluid Flow, vol. 28, no. 3, pp. 469-482, 2007.

[9] M. Gavara, "Natural convection in a vertical channel with arrays of flush-mounted heaters on opposite conductive walls," Numerical Heat Transfer, Part A: Applications, vol. 62, pp. 111-135, 2012.

[10] D. Mishra, K. Muralidhar and P. Ghoshdastidar, "Computation of flow and heat transfer around a vertical discrete protruding heater using an operator-splitting algorithm," Numerical Heat Transfer, Part A: Applications, vol. 28 , no. 1, pp. 103-119, 1995.

[11] H. Türkoğlu, N. Yücel, "Mixed convection in vertical channels with a discrete heat source," Heat and Mass Transfer, vol. 30, no. 3, pp. 159-166, 1995.

[12] S. Du, E. Bilgen, P. Vasseur, "Mixed convection heat transfer in open ended channels with protruding heaters," Heat and Mass Transfer, vol. 34, no. 4, pp. 263-270, 1998.

[13] P. Guimarães, G. Menon, "Combined free and forced convection in an inclined channel with discrete heat sources," International Communications in Heat and Mass Transfer, vol. 35, no. 10, pp. 1267-1274, 2008.

[14] L. Boutina, R. Bessaïh, "Numerical simulation of mixed convection air-cooling of electronic components mounted in an inclined channel," Applied Thermal Engineering, vol. 31, no. 11-12, pp. 2052-2062, 2011.

[15] G. Xu, K. Tou and C. Tso, "Numerical modelling of turbulent heat transfer from discrete heat sources in a liquidcooled channel," International Journal of Heat and Mass Transfer, vol. 41, no. 10, pp. 1157-1166, 1998.

[16] C. Gururaja Rao, C. Balaji, S. Venkateshan, "Effect of surface radiation on conjugate mixed convection in a vertical channel with a discrete heat source in each wall," International Journal of Heat and Mass Transfer, vol. 45, no. 16, pp. 3331-3347, 2002.

[17] R. Mathews, C. Balaji, "Numerical simulation of conjugate, turbulent mixed convection heat transfer in a vertical channel with discrete heat sources," International Communications in Heat and Mass Transfer, vol. 33, no. 7, pp. 908-916, 2006.

[18] G. Rao, G. Narasimham, "Laminar conjugate mixed convection in a vertical channel with heat generating components," International Journal of Heat and Mass Transfer, vol. 50, no. 17-18, pp. 3561-3574, 2007.

[19] R. Mathews, C. Balaji, T. Sundararajan, "Computation of conjugate heat transfer in the turbulent mixed convection regime in a vertical channel with multiple heat sources," Heat and Mass Transfer, vol. 43, no. 10, pp. 1063-1074, 2006.

[20] B. Premachandran, C. Balaji, "Conjugate mixed convection with surface radiation from a vertical channel with protruding heat sources," Numerical Heat Transfer, Part A: Applications, vol. 60, pp. 171-196, 2011.

[21] S. Londhe and C. Gururaja Rao, "Interaction of surface radiation with conjugate mixed convection from a vertical channel with multiple discrete heat sources," Heat and Mass Transfer, vol. 50, no. 9, pp. 1275-1290, 2014.

[22] ANSYS Inc., ANSYS Fluent User's Guide Release 15., 2013. 